\title{
Identidad política en los relatos del nueve de abril de 1948 en Boyacá*
}

\author{
CAMILA ANDREA BOHÓRQUEZ AUNTA ** \\ ERIKA LILIANA GONZÁLEZ GONZÁLEZ *** \\ ALEXANDER TORRES SANMIGUEL *****
}

Recepción: 20 de enero de 2020

Aprobación: 25 de febrero de 2020

Forma de citar este artículo: Bohórquez, C. A. González, E \& Torres, A. (2020). Identidad política en los relatos del nueve de abril de 1948 en Boyacá. Cuadernos de Lingüística Hispánica, (35), 131-153.

Thttps://doi.org/10.19053/0121053X.n35.2020.10520

* Artículo de investigación. Presenta los resultados de la tesis de la Maestría en Lingüística intitulada "Identidad política en los relatos del 9 de abril de 1948 en Boyacá".

** Docente investigadora de la Universidad de Boyacá, adscrita al grupo de investigación Comunicación UB. Magíster en Lingüística, Universidad Pedagógica y Tecnológica de Colombia UPTC. Comunicadora Social, Universidad Nacional Abierta y a Distancia UNAD. cambohorquez@uniboyaca.edu.co @ https://orcid.org/ 0000-0001-7597-2638

*** Docente investigadora de la Institución Educativa Julius Sieber. Magíster en Lingüística. Especialista en Gerencia Educacional. Licenciada en Idiomas Modernos Español-Inglés, Universidad Pedagógica y Tecnológica de Colombia UPTC. erikaliliana. gonzalez@uptc.edu.co @https://orcid.org/0000-0002-5606-982X

***** Docente investigador de la Universidad Santo Tomás, adscrito al grupo de investigación Comunicación, Paz-Conflicto. Doctor en Lenguaje y Cultura de la Universidad Pedagógica y Tecnológica de Colombia. Magíster en Comunicación de la Pontificia Universidad Javeriana. Psicólogo de la Universidad Nacional de Colombia. alexandertorres@usantotomas.edu.co Chttps:// orcid.org/ 0000-0002-1880-4352 


\section{Resumen}

El propósito de este artículo es analizar cómo afecta la identidad política la construcción de los relatos del 9 de abril de 1948 en Boyacá. Se enmarca en el paradigma histórico hermenéutico, utiliza el enfoque cualitativo y el modelo sociolingüístico orientado hacia el análisis del discurso del testimonio. Para ello, se realizó un trabajo de campo a partir de entrevistas semiestructuradas, que dejan un corpus conformado por 23 relatos de 16 testigos oriundos de Boavita, Cómbita y Tunja. Los resultados están enfocados en comprender la influencia de la identidad política del hablante en la narración de los acontecimientos del pasado.

Palabras clave: análisis del discurso; identidad política;ideología;memoria histórica;9 de abril de 1948.

\section{Political Identity in the Narratives of April 9, 1948 in Boyacá}

\section{Abstract}

The purpose of this article is to analyze how political identity affects the construction of the narratives of April 9, 1948 in Boyacá. It is framed under the historical-hermeneutic paradigm, the qualitative approach and the sociolinguistic model oriented in the analysis of testimony. The field work was carried out based on semi-structured interviews that build a corpus of 23 stories of 16 witnesses from Boavita, Cómbita and Tunja. The results are focused on understanding the influence of the speaker's political identity on the narration of past events.

Keywords: analysis of discourse; political identity; ideology; historical memory;April 9;1948. 


\section{Identité politique des récits historiques du 9 avril 1948 dans le Boyacá}

\section{Résumé}

Le but de cet article est d'analyser la manière dont l'identité politique affecte la construction des récits historiques du 9 avril 1948 dans le Boyacá. Il s'inscrit dans le paradigme historique herméneutique, il utilise l'approche qualitative et le modèle sociolinguistique orienté vers l'analyse du discours du témoignage. Pour ce faire, un travail in situ a été réalisé à partir d'entretiens semi-structurés, qui donnent lieu à un corpus composé de 23 récits de 16 témoins de la ville de Tunja et de villages de Boavita, et de Cómbita. Les résultats tournent autour de la compréhension de l'influence de l'identité politique du locuteur dans la narration des événements passés.

Mots clés: analyse du discours; identité politique; idéologie; mémoire historique; 9 avril 1948.

\section{Identidade política nas histórias de 9 de abril de 1948 em Boyacá}

\section{Resumo}

0 objetivo deste artigo é analisar como a construção das histórias de 9 de abril de 1948 em Boyacá afeta a identidade política. Está enquadrado no paradigma histórico hermenêutico, utiliza a abordagem qualitativa e o modelo sociolinguístico orientado para a análise do discurso do depoimento. Para isso, foi realizado um trabalho de campo a partir de entrevistas semiestruturadas, que deixam um corpus composto por 23 histórias de 16 testemunhas de Boavita, Cómbita e Tunja. Os resultados são focados no entendimento da influência da identidade política do falante na narração de eventos passados.

Palavras-chave: análise do discurso; identidade política; ideologia; memória histórica; 9 de abril de 1948. 


\section{Introducción}

Transcurren los años 30 y 40 en Colombia y la violencia que se manifiesta en cada pueblo, municipio, provincia o departamento, a causa del bipartidismo, se agudiza con el paso del tiempo. El asesinato del líder político Jorge Eliécer Gaitán el 9 de abril de 1948 en la ciudad de Bogotá, exacerba la violencia en el país, en la que se manifiestan luchas guiadas por el poder, las ideologías liberal y conservadora, y las identidades políticas.

Este acontecimiento conocido como "El Bogotazo", que para algunos historiadores marca el inicio del periodo denominado como "La Violencia" en Colombia, deja varios interrogantes en la historia de un país sin memoria, circunstancia que se evidencia en la carencia de estudios e investigaciones orientados a comprender lo ocurrido ese 9 de abril, especialmente en el departamento de Boyacá. Una problemática pertinente no solo para la historia y los historiadores, sino para las ciencias sociales y humanas en general, y en especial para la lingüística, por su interés en advertir el valor del lenguaje en los acontecimientos del pasado, integrando el análisis del discurso del testimonio como herramienta que permite desentrañar las voces que han permanecido silenciadas por años (Ricoeur, 1995). Lo que posibilita, además, identificar la forma en que la identidad política del narrador afecta la construcción e interpretación de este acontecimiento en particular.

La sabiduría de los abuelos que aportaron con su relato a esta investigación, confirma, contrasta o completa la información que la historia ha dado a lo largo de los años. Esa dimensión histórica se refleja en acciones que se actualizan al ser contadas en un presente que es capaz de dar cuenta del contexto en el que vivió cada testigo. Es necesario resaltar el valor que proporcionan las voces particulares que no se mencionan en la historia, porque es desde estas que se nutren los acontecimientos. En otras palabras, el testimonio - en su singularidad y en su individualidad - es una importante fuente de investigación, pues contribuye a la historia que difiere de alguna manera de la historia que se ha plasmado a partir de las versiones oficiales.

Todo lo anterior hace significativa la investigación, especialmente si se tiene en cuenta que hay muy pocos artículos que se enfocan en temáticas afines, y nos lleva a plantear como objetivo general el análisis de la construcción de la identidad política, como eje del discurso en los relatos del 9 de abril de 1948 en la ciudad de Tunja y en los municipios de Cómbita y Boavita, del departamento de Boyacá. 


\section{Referentes teóricos}

Algunos de los aportes conceptuales que fundamentan la investigación son: identidad política, ideología, poder, memoria histórica, mecanismos discursivos, narrativa, testimonio-relato y análisis del discurso.

\section{Aproximaciones a la identidad política}

Para esta investigación es importante tener presente que cada testigo en su narrativa deja entrever las acciones que lo representan con unos factores característicos que hacen evidente una ideología particular o una adscripción política específica, que se manifiesta en los mecanismos discursivos revelados en su actuar dentro de una colectividad. La identidad política se infiere a partir del lenguaje y las nominaciones de cada adscripción. El sujeto narra su propia realidad, trayendo a colación su percepción desde las particularidades con las que puede describir un acontecimiento que ha experimentado y evidenciado.

La identidad en general permite postular de sí mismo una serie de identidades, que ponen en juego, en determinados contextos, posiciones a partir del lenguaje. Dichos postulados se representan en la construcción de un repertorio de actitudes, de palabras, enunciados y gestos, que se reflejan en cada uno de los hablantes. Expresiones como "éramos liberales" evocan, por tanto, una identificación dentro de una colectividad.

Es por ello que nadie puede identificar la identidad de sí mismo, sin haberlo hecho a partir de los otros, quienes nominan, comparan y descubren diversas identidades en una sociedad (Arendt, 2009).

La identidad personal se constituye a través del factor tiempo, el cual incide en la estructuración de cada relato de vida, tomando en cuenta que el narrador se sitúa en un momento y en un contexto determinado, en el que desglosa la construcción del sí. Cada uno de los hablantes que narra su relato se sitúa en su experiencia desde niño, pero con el paso de los años es capaz de interiorizarlo y evidenciarlo a partir de la oralidad. La identidad es aquello que le permite ser.

Dentro de los diferentes tipos de identidad se encuentra la identidad política, aquella que se enfoca en la construcción de las particularidades que surgen en las tradiciones y que se fortalecen o desaparecen desde la experiencia del si mismo, vivencias que pueden comprenderse a través del lenguaje, puesto que solo mediante las palabras y, específicamente, mediante el discurso, se puede demostrar "una alianza entre el pueblo para un propósito concreto, como el de organizarse para gobernar" (Arendt, 2009, p. 28). 
El interés individual por pertenecer a los grupos sociales "ha llevado a una mejor capacidad de predicción con respecto a las actitudes y los comportamientos políticos de los individuos" (Greene, 2004, p. 136). Comportamientos que permiten inferir por qué la identidad surge del compartir palabras (lexis) y acciones (praxis); una relación a la que Arendt (2009) denomina como la esfera política, de gran importancia para comprender las diferentes formas de organización de las comunidades humanas y su adscripción ideológica o política.

\section{Ideologías políticas}

Ahora bien, desde la perspectiva de las oposiciones políticas que polarizaron al país entre liberales y conservadores, la ideología se concibe como el grupo de ideas donde se fundamentan las prácticas de las estructuras sociales (entendidas como los diferentes partidos políticos y la Iglesia, entre otros) (Van Dijk, 2005). Se entiende que no se ejercen en la individualidad, sino en la colectividad, en grupos conformados y establecidos, reconocidos y legitimados por los miembros de esta misma.

Por consiguiente, la ideología contribuye a elaborar una concepción de mundo en la que imperan los lineamientos propuestos por unos cuantos y que son aceptados, aunque no del todo, por la mayoría. Dentro de este constructo se pueden tener en cuenta las creencias que posee el grupo, así como los valores axiomáticos que controlan y organizan las actitudes y acciones-procesos que se desarrollan en este. Es así como desde su posición de individuo que participa de una colectividad, el testigo del 9 de abril erige su propio pensamiento para llevar a cabo acciones representativas que considera propias y adecuadas a los principios propuestos por el partido político al que pertenece. Según el relato de algunos testigos, identificarse con el color rojo o azul constituye una decisión particular, dependiendo del partido político con el que simpatizan.

Para alcanzar un objetivo propuesto, las ideologías se permiten el uso de la violencia como una herramienta eficaz y rápida, dejando de lado las leyes que rigen la sociedad, porque ellas se convierten en un obstáculo para la consecución de sus propósitos. Así, lo que triunfa será la idea sobre el hecho; los dos, ideas y hechos, se articulan para dar un sentido razonable a las acciones que se ejecutan, lógica que contribuye a afirmar que algunas de ellas son fundamentales en la consecución de la igualdad de las sociedades.

Son tales las proporciones que pueden alcanzar las ideologías cuando sus consignas se convierten en axiomas, que conducen al propio exterminio de la sociedad. Realidad que se reflejó en cada municipio de Boyacá al conocerse la noticia del asesinato 
de Gaitán, con el estallido de una violencia bipartidista que puso en riesgo la vida en defensa de una tradición política.

\section{Los referentes de poder}

Hablar de identidad política e ideologías hace necesario referirse al poder, visto aquí como la capacidad, habilidad o facultad del individuo para ejercer control sobre otros, que puede adquirirse de forma voluntaria o a partir de la imposición, dependiendo del contexto y la situación dada.

Escuchar a los abuelos boyacenses narrar las vivencias de los acontecimientos ocurridos el 9 de abril de 1948 en el departamento, demuestra que la lengua se convierte en una forma de poder que se ejerce a través de las palabras y de los discursos, que funcionan, junto a las tradiciones, como formas de expresión de una colectividad. Dicho poder se visualiza mediante referentes que reflejan una lucha bipartidista.

El poder se manifiesta en las acciones del actor o los actores que influyen en las decisiones de una colectividad. Es el hilo conductor entre lo dicho y los referentes de poder, los cuales se encuentran en los relatos a través de los mecanismos discursivos utilizados por los narradores que describen el control ejercido por los líderes políticos del momento. Estos referentes resaltan el constante enfrentamiento entre quien lidera y su contrapoder, entre dominantes y dominados; pugna que constata cómo se constituyen las estructuras de la sociedad, pues de cierta manera determinan las reglas del juego por las cuales se rigen los individuos (Castells, 2009).

\section{La memoria histórica}

El concepto de memoria no es igual que el de historia. La historia, en términos generales, se encarga de estudiar los hechos del pasado de la humanidad y lo que los rodea; y la memoria es un concepto ideológico e historiográfico que viene de la reconstrucción subjetiva de los hechos que se han evidenciado, marcados por un tiempo y espacio determinados (Nora, 1993). Así, la memoria puede construirse a través de la individualidad o desde lo colectivo, en cambio la historia es la recopilación del trabajo de memoria con base en hechos trascendentes y datos verificables.

Paul Ricoeur, en su libro La memoria, la historia y el olvido (2004), hace un recorrido en favor de la memoria como matriz de la historia. Para el autor, la memoria ha de estudiarse desde la dimensión individual y colectiva, donde lo individual resalta la importancia del recuerdo propio y único, el cual mantiene un vínculo con la conciencia del pasado. Y para los propósitos de este artículo, la memoria es la posibilidad que tienen 
los hablantes, por reencontrarse con los acontecimientos del 9 de abril, de volver a sentir esa realidad que está lista para ser contada y traer al presente, a través de sus expresiones, esas particularidades que hacen de cada relato único.

La memoria se convierte en uno de los principales aportes para esta investigación, pues permite revivir escenarios del pasado, episodios de violencia, connotaciones de pertinencia para la comprensión del relato que posibilitan el acercamiento a aquellos que han sido testigos y que han esperado años para revelar su testimonio. De esta manera, construye e implica reafirmar identidades y voces desconocidas de los hechos del pasado, "es un acto político y una práctica social [...] es una esfera donde se tejen legitimidades, amistades y enemistades políticas y sociales" (Centro Nacional de Memoria Histórica [CNMH], 2013, p.13).

Ante la relación necesaria entre memoria e historia se crea el concepto de memoria histórica, entendida como el conjunto de recuerdos que son transmitidos entre los individuos de distintas generaciones. Así, la memoria necesita de la historia, ya que sin ella se convierte en un recuerdo (Nora, 2008). Entonces, en esta investigación es fundamental tomar los testimonios del 9 de abril, puesto que aportan datos significativos que no se evidencian en la historia oficial y, en la misma medida, permiten comprender lo sucedido en un contexto determinado.

Walter Benjamin (citado en Fressoli, 2010) descubre en la memoria dos factores fundamentales para el análisis: la vivencia y la experiencia. La primera, reorigina el sentido que tiene El Bogotazo en la historia de Colombia y dimensiona las características del suceso de acuerdo con el contexto del que habla; y la segunda, permite vincular las adscripciones políticas del hablante, las cuales le insertan un valor semántico esencial para el testimonio, que posibilita la confrontación de los acontecimientos desde el pasado y el presente. Además, la pertenencia del testigo a un partido político determina la secuencia de lo que narra y delimita su testimonio en la descripción de los acontecimientos que él considera significativos, eludiendo datos e incluso sucesos, personajes o acciones del mismo testimonio.

\section{Análisis del discurso}

El análisis del discurso permite visualizar las categorías con las que se transmite el mensaje, a través del examen el texto y el contexto, que es fundamental en la interpretación de los testimonios del 9 de abril, desde donde se ve no solo el texto, sino todas aquellas cualidades que lo hacen emblemático. 
El discurso es lo que impacta del acto comunicativo, el cual mantiene una serie de regularidades que le dan coherencia y cohesión. Para Wodak (2003), el discurso se entiende como un conjunto complejo de prácticas sociales lingüísticas que se manifiestan en ámbitos como la oralidad.

El análisis del discurso sobre los testimonios alrededor del 9 de abril intenta, desde las características propias de cada testigo, explicar la subjetividad de los acontecimientos que permiten armar y analizar el corpus que construye la memoria individual. "Este tipo de discurso deriva de los esfuerzos individuales por explicar y explicarse la subjetividad de las vivencias, donde los relatos - transcripciones de lo oral- responden a la necesidad humana de contar las experiencias" (Meza, 2007, p. 8).

Por tanto, es importante que el sujeto en su relato exprese sus vivencias, para que este pueda ser sistematizado y contribuya a la memoria histórica de un hecho trascendental en el departamento de Boyacá y Colombia. Pues, el análisis del discurso permite comprender la relación necesaria entre el texto (lo que se narra) y el contexto (factores que intervienen en el momento de la narración); es decir, desde la postura que asume la experiencia en el testigo al pertenecer a un partido político (liberal 0 conservador).

\section{Testimonio, relato y narrativa}

Los postulados teóricos que aquí se presentan están sustentados bajo la teoría de la narrativa de Mieke Bal (1990) y los métodos para su recolección propuestos en el libro del CNMH: Recordar y narrar el conflicto (2013).

Así, el testimonio es un texto narrativo que permite el acercamiento a la realidad percibida por el testigo, narrada con base en sus experiencias y vivencias, resaltando lo significativo desde su punto de vista sobre un acontecimiento particular; lo cual hace que cada testimonio desde su pequeñez y su individualidad aporte a la memoria. De esta manera, el compilado de sucesos del 9 de abril narrados por un testigo se complementa, amplía o coincide con los relatos de otros testigos; esta situación hace pertinente el cruce de categorías en el análisis de la investigación, pues es esa secuencialidad la que le otorga sentido a los hechos ocurridos en Cómbita, Boavita y Tunja, municipios relevantes en el departamento de Boyacá, así como en la historia de Colombia.

En efecto, el relato se convierte en una parte constitutiva de la investigación, donde se hace necesaria una comprensión de los puntos de vista singulares, subjetivos 
y cambiantes, dependiendo de las situaciones que se producen en cada narración, de donde emergen dos elementos fundamentales: el tiempo y el espacio.

Al referirnos al tiempo se debe mencionar el término evento, entendido como una unidad cronológica desde la que se organizan y estructuran las memorias. Los relatos de los hablantes están constituidos sobre dicha base, y el análisis de los eventos del 9 abril, anota Portelli (como se citó en CNMH, 2013), facilita identificar cómo la memoria de ciertos periodos se organiza bajo ciertas temporalidades, pero, además, los modos (las claves) en que cada testigo narra y da coherencia a sus historias. Es necesario resaltar que en cada relato se puede corroborar la funcionalidad de los tres patrones que el hablante asume para organizar su recuerdo: la esfera de la política, la vida de la comunidad y la experiencia personal.

De acuerdo con estos últimos patrones, los testimonios que conforman el corpus de la presente investigación están determinados por dicha esfera que dirige la temática de los relatos; una vida en la comunidad, donde se ejecuta cada acción, y la experiencia personal que da significado particular a las vivencias del testigo. Estos elementos permiten enfocar desde la lingüística un análisis que visualice la manera en que se preservan las mismas estructuras lingüísticas con el pasar de los años, para darle un valor significativo al testimonio.

\section{Mecanismos discursivos}

Los elementos lingüísticos como los pronombres personales, demostrativos y posesivos, las desinencias verbales, los adverbios de tiempo y de lugar, deben ser comprendidos en una totalidad que configura un significado, elaborado por un hablante que remite a un pasado y que se actualiza al momento de ser contado. En el mismo sentido, la deixis se presenta como el elemento que permite la relación discursiva entre lo expresado en cada relato y los elementos lingüísticos, es decir, entre lo sociológico y lo lingüístico. Es el sistema de referencias internas al discurso, cuyo eje es el yo, donde los mecanismos discursivos constituyen indicadores que ubican al texto en el género narrativo.

Para Duranti (2000), la deixis es el mecanismo discursivo que ayuda a definir las identidades y es la herramienta ideal para comprender las relaciones de poder en un evento comunicativo. Los narradores utilizan formas específicas para denominar los referentes, en especial aquellos que tienen relación con la política, elementos lingüísticos que ubican al oyente en un contexto y época determinada. Ejemplo de ello se ve en el enunciado "El viejo ese duró los cuatro años, el viejo Rojas Pinilla". 
Los pronombres personales tú y usted se referencian en la clasificación de deixis social, puesto que manifiestan maneras de expresión formales e informales, de confianza o desconfianza, cercanía o alejamiento, amigo o enemigo en el relato, revelan, además, el grado de respeto o intimidad, distanciamiento o insulto (Fillmore, 1979). Al hacerse explícito el pronombre personal nosotros, ocurre una adhesión del individuo a la colectividad con la que se siente identificado, en cuanto a que comparte sus formas de pensar y de actuar.

Apartirdel análisis de los relatos, se puede identificar la presencia de los mecanismos discursivos, específicamente la deixis de tipo personal, social y espaciotemporal, marcadores que indican en cada narración lo vivido por el sujeto, relaciones exofóricas y endofóricas que le dan sentido a los acontecimientos y que hacen explícito el valor de cada uno de ellos; además, actualizan y revelan comportamientos individuales 0 colectivos al contar un suceso, dándole la importancia a las partes del discurso que el hablante expresa que no son visualizados en el relato sino a través de su estudio analítico.

Las categorías expuestas anteriormente permiten llegar a la comprensión y a la interpretación de 16 relatos que dan a conocer cómo se vivieron los sucesos de un hecho trascendental en Colombia, en el que a partir del análisis se visualizan las causas y consecuencias en el departamento de Boyacá y la manera cómo la identidad política del hablante podría afectar la construcción de su relato.

\section{Metodología}

De acuerdo con los objetivos propuestos, la investigación se enmarca en el paradigma histórico-hermenéutico, el cual le permite al investigador examinar la subjetividad desde donde se narra el relato, lo que implica el intento por discernir los acontecimientos del pasado a través de la memoria particular, sin dejar de lado la importancia del individuo, quien asume un propósito comunicativo en el momento en el que se realiza la entrevista, con el cual interpreta la realidad de una situación que parte de su experiencia y su vivencia.

De esta manera, esta investigación se fundamenta en el enfoque cualitativo, porque su perspectiva epistemológica se orienta en las realidades humanas y sociales de testigos que vivieron el 9 de abril en Boyacá, por lo que examina la situación percibida, el contexto de los acontecimientos y las interpretaciones críticas, centrándose en aquellas de interés en la sociedad (Sampieri, 1998). Este enfoque permite comprender la problemática de la investigación en su interés por estudiar a la sociedad, en cuyo caso se plantea descubrir la 
incidencia de las identidades y las ideologías, y la manera en que se manifiestan y afectan la construcción del relato.

En efecto, la apuesta sociolingüística que rige esta investigación se presenta como mecanismo constitutivo, intencional y regulativo de la comunicación lingüística, que permite interpretar los fenómenos a través de las representaciones sociales y descripciones de los recursos lingüísticos y socioculturales de los hablantes de cada uno de los relatos. Este modelo se hace pertinente en la investigación, porque permite estudiar las prácticas sociales, y a través del lenguaje, los discursos de poder, donde se encuentran inmersos los relatos.

\section{Recolección de información}

En cuanto a la recolección de la información, se usó la observación directa, entrevistas semiestructuradas y documento escrito; es decir, la transcripción de cada uno de los relatos recolectados, el respectivo análisis y la escritura del texto final; lo cual es sintetizado por Corbetta (2003) en "observar, preguntar y leer" (p. 302). Por tanto, se realizaron entrevistas semiestructuradas en Tunja, Cómbita y Boavita, para la conformación del corpus; la mayoría de los testigos tiene una segunda entrevista, lo que permitió ampliar y nutrir cada unidad de análisis, con base en algunas preguntas orientadoras.

Los relatos que conforman el corpus se seleccionaron por medio de la técnica bola de nieve. El primer testigo, con su relato, proporcionó información acerca de la procedencia y la localización de otros informantes; a su vez, el segundo testigo, mediante su narración y de acuerdo con su vivencia, aporta y ratifica lo que el primer testigo refirió, y del mismo modo ocurre con los relatos restantes.

Es imprescindible mencionar que lo que se pretendió mostrar en la investigación es la identidad política en la construcción de los relatos del 9 de abril, para ello emergieron las categorías como la ideología, el poder y la identidad política, las cuales se analizaron desde la referencia situacional que se dio en los relatos, y que se evidenció mediante los mecanismos discursivos, tales como deixis de tipo personal, temporal, espacial y social, y en ellas los pronombres, adverbios de lugar, de tiempo y algunos formas verbales.

\section{Caracterización del corpus y de los hablantes}

Esta investigación cuenta con un corpus conformado por 23 relatos de 16 testigos, oriundos de Boavita, Cómbita y Tunja, los cuales cumplen con las siguientes características: quienes vivenciaron los acontecimientos que sucedieron en su municipio, 
vereda, o ciudad el 9 de abril de 1948; la edad de los testigos osciló entre 69 y 100 años; los sujetos se ubican en una colectividad, donde construyen su relato; son testimonios representativos en su forma oral, pues conservan diferentes entonaciones que marcan énfasis de emotividad en la expresión y algunos factores identitarios con los que se construye su narración.

La forma en que se relatan los acontecimientos conserva una secuencia narrativa coherente y cohesiva; existe un predominio de expresiones que describen violencia, poder e ideología; las narraciones presentan características fonéticas propias del habla boyacense: aféresis, apócope, permutación, asimilación, metátesis, entre otras; reiteración en palabras que indican la temporalidad y espacialidad; coocurrencia en sucesos que denotan violencia; manejo de espacios, tonalidades, acentos que refieren un momento específico; y elementos endofóricos y exofóricos del testimonio.

\section{Procedimiento}

En un primer acercamiento se hizo la observación de campo. Acto seguido, se llevó a cabo una primera entrevista que cumplió con los criterios anteriormente descritos. El acceso a la información se complejiza dependiendo el lugar donde el relato se recolectó; es así como, en Cómbita y Tunja, los sujetos entrevistados cuentan sus vivencias de forma escueta, mientras que en Boavita, las personas, tanto hombres como mujeres, son renuentes a contar cualquier hecho histórico que tenga que ver con el 9 de abril del 48, aspecto que se puede entender dada la trascendencia de este municipio en el reclutamiento de "Los Chulavitas".

Después de tener la información primaria en formato audio, se procedió a la transcripción de las entrevistas con base en el método de etiquetado, transcripción y codificación de corpus orales de Joaquim Llisterri (1999). Este permite mantener un registro cercano a la intención comunicativa del hablante, puesto que las entrevistas conservan regionalismos y expresiones autóctonas características de un habitante nacido en dicha época y en los lugares relacionados.

Posteriormente, se realizó una segunda entrevista en la que se ampliaron los datos y se confirmaron estructuras lingüísticas y paralingüísticas que se expresan tal como fueron dichas la primera vez. En seguida, se procedió al análisis de los datos que emergieron de cada uno de los corpus, clasificándolos en las categorías antes expuestas. Para ello se utilizó el programa TextStat 3.0, que arrojó el índice de coocurrencias léxicas, frecuencias de uso y análisis textual. 
Los datos o conceptos que se analizan emergen de los corpus y conforman las categorías referentes de poder, identidad política, ideología y memoria histórica, que se hacen explícitas en cada uno de los enunciados y, con ellas, los mecanismos discursivos que permiten visualizar la interrelación entre los factores sociológicos y su influencia en las estructuras lingüísticas que utilizan los hablantes en la narración. Para el desarrollo de esta fase se utilizaron los programas: ATLAS.ti 7.4 y Tropes V7.2.

\section{Resultados}

A continuación, se presentan algunos de los resultados obtenidos en los relatos que posibilitaron el entrecruzamiento de conceptos emergentes para la interpretación y, por ende, la comprensión de los acontecimientos objeto de estudio a partir de las dimensiones y categorías anteriormente mencionadas. Para ello, se presentan algunos ejemplos procedentes del análisis hecho al narrador 01, nominado bajo el código sociolingüístico G3I1H07, (generación, nivel de instrucción, género: hombre o mujer, número de entrevista).

\section{Ejemplo número 1:}

\section{«fue harto jodido el problema»}

La frase permite visualizar el nivel en el que el hablante ubica el acontecimiento que narra. Hace referencia a la violencia vivida durante el 9 de abril y las situaciones que emergen a partir de la lucha bipartidista. Esta frase se sitúa en la categoría referentes de poder, puesto que el problema expresado remite a una condición de contrariedad entre los seguidores de cada partido político.

El adverbio de cantidad "harto", expone el tamaño de la situación que percibe el narrador, quien además agrega "jodido" para hacer referencia a la puja bipartidista por el control político del municipio. Esta expresión deja entrever la experiencia y la vivencia que el hablante percibe en su niñez, quien se enmarca en una connotación característica del habla boyacense que se utiliza para calificar y describir algo como demasiado difícil, muy complicado, temible, inexplicable, terrible, entre otros.

\section{Ejemplo número 2:}

"a cada casa donde éramos liberales, mi papá era un gran liberal, entonces llegaba la gente, bueno iusted es mío! o lo mato acá”.

El verbo éramos hace referencia al grupo en el cual se incluye el sujeto. Se ubica dentro de una ideología y se reconoce como parte de ella; además, hace alusión a la 
identidad política que caracteriza a la familia de quien cuenta su historia. El hablante menciona a su papá, lo ve como un modelo y lo exalta utilizando el adjetivo gran, acompañado de la filiación política de la familia. Mi papá era un gran liberal, es una aclaración que hace el hablante dentro de lo que está expresando.

La gente, se refiere a los participantes del partido contrario, a los que parece que no son dignos de ser nombrados ni reconocidos; en cambio, es necesario mencionar todas las acciones que han llevado a cabo. El pronombre en segunda persona - ustedindica una distancia entre un hablante y un oyente; asimismo expresa la posición de ventaja en la que se encuentra quien, dentro del relato, pronunció la expresión, y tiene la propiedad para matar o dejar vivir por no ser del mismo partido político, lo que hace que esta frase se pueda incluir en la categoría de referentes de poder.

Ejemplo número 3:

"Mi [papasito] todo temblando, todo esto, mi [papasito] está por allá, aquel lado, [pua' lla] metido entre un montón de caña porque era que llegaban de a idiez policías!"

El enunciado refleja el sentimiento de temor frente a un actor que tiene el poder; la posición social en la que se encuentra lo hace dominado o víctima. Igualmente, la filiación política se convierte en símbolo que genera un riesgo para la vida. Los principios que orientan a cada uno de los partidos políticos crean un sentido de pertenencia en que 0 se mata 0 se muere. Lo que indica que las ideologías dominan las identidades, y estas dos a su vez expresan unos referentes de poder que van desde lo individual hasta lo colectivo; por tanto, es común escuchar en los relatos que se actuaba en grupo y en nombre de una ideología.

\section{Ejemplo número 4:}

\section{"había un señor que era el [feje] del partido conservador"}

La ideología de los actantes del relato se hace explícita al designar a uno de los actores sociales. A su vez, se observa que cada partido político tiene líderes que asumen su rol y lo ejercen mediante la coacción. Las relaciones de poder están marcadas y delimitadas por las mismas personas de la comunidad, quienes apelan al temor del otro para lograr adhesión de grupo. 


\section{Ejemplo número 5:}

\section{"Entonces fue tremendo, quien no le iba o le decían: bueno, es que tiene que ir conmigo, o si no, tenga"}

Esta frase expresa connotaciones que resaltan la violencia bipartidista de la época, deja entrever las consecuencias de pertenecer a un partido u otro. Nuevamente trae a colación el adjetivo tremendo, que encierra la percepción del hablante frente a un acontecimiento, ubicándolo dentro de sentimientos de sobrecogimiento, susto, miedo 0 terror.

Luego viene una expresión de poder: quien no le iba, que, de acuerdo con el contexto, el verbo iba se refiere a la pertenencia al otro partido; por tanto, lo que continúa conlleva las consecuencias de no pertenecer a un color, en términos que aluden al uso abusivo del poder: es que tiene que ir conmigo, o si no, tenga.

Todo ello indica contrapoder, fuerzas de dominación y la violencia que ubica al sujeto en peligro de muerte al reafirmar su identidad política. El verbo tenga, por supuesto, encierra todas aquellas situaciones que agreden la integridad física de ser humano y permite comprender el miedo con el que el sujeto menciona el conflicto en la región.

\section{Ejemplo número 6:}

\section{"Así era la vaina"}

Esta expresión se repite con frecuencia en el relato, pues encierra el conflicto presentado durante la época y específicamente este día trascendental para el país. $L a$ vaina, en el territorio boyacense, evoca una cosa 0 un hecho que, por complicado de explicar, se reduce en una connotación. La frase es utilizada para omitir la violencia bipartidista en Cómbita, manifestando desde su posición como liberal las complicaciones que traía la pertenencia a este partido en un sector donde imperaba el Partido Conservador.

\section{Ejemplo número 7:}

\section{"Eso hacían lo que querían delante de los papás, con las hijas"}

Esta frase, dada la época, tiene una connotación que integra el vínculo familiar y los lazos de protección, en especial, con el género femenino. El tesoro de un liberal se ve reflejado en sus hijas; por tanto, el abuso, la amenaza, el irrespeto iba dirigido a ellas, mostrando de manera cruel y salvaje el poder de unos sobre otros y forzando una guerra 
que dejaría graves consecuencias. La impresión del hablante frente a estos sucesos se refleja en las expresiones y atenuaciones que evocan un repudio por lo evidenciado.

\section{Ejemplo número 8:}

\section{“ella era gorda y era una gran persona, era la señora [simpatícima] (...) de una vez la mataron y le mandaron una poca de gasolina y la quemaron"}

En este enunciado se señala a un individuo perteneciente al Partido Liberal y se conceptualiza en, primer lugar, dentro del adjetivo singular femenino gorda, el cual, en el contexto del habla combitense, significa la caracterización de una persona con recursos económicos y calidad de vida estable. En segundo lugar, la califica como gran persona, frase que lleva a su carácter y comportamiento con los otros, expresa su generosidad y su amabilidad con sus paisanos. Por último, simpatícima, adjetivo que expresa belleza y que acompaña al sustantivo señora, el cual permite inferir que ella era de una edad adulta.

Las características mencionadas por el hablante muestran admiración como consecuencia de una misma identidad política. Debido a que esta persona es liberal y además cuenta con los recursos necesarios, se convierte en objetivo claro para la oposición, del cual refiere una caracterización que evoca odio y se marca en varios puntos del relato.

La acción ejercida sobre la señora se señala como la consecuencia de pertenecer al Partido Liberal, donde un ellos, acaba de forma salvaje y sanguinaria con la vida de la mujer. Este hecho desentierra un dolor que se evidencia en el hablante, para quien, como niño en el momento de los hechos, este episodio fue uno de los más fuertes que dejó para su memoria el 9 de abril de 1948.

Ahora bien, de los sucesos de El Bogotazo narrados por un testigo, que se complementan, amplían o coinciden con los relatos de otros testigos, situación pertinente frente al cruce de categorías en el análisis de la investigación, pues es esa secuencialidad la que le otorga sentido a los hechos ocurridos en Cómbita, Boavita y Tunja, municipios relevantes en el departamento de Boyacá, y así mismo en la historia de Colombia, se presentan los siguientes ejemplos:

- G3I1M16L: "Todo un día viernes del 48, un 9 de abril me vine con mi mamá del campo de Cómbita a vender nuestro mercadito aquí a este pabellón y **tando vendiendo en eso de las dos de la tarde echamos a oír un [gritazón], un [llorazón] y [balazón], **tonces echaron a decir que: - < iMataron a Gaitán, mataron a Gaitán, que Mataron a Jorge Eliécer Gaitán!>”. 
- G3I1M02C: "[esoera] el que iba saliendo lo iban imatando!, de las casas, y eso era [pa**] que recogían la gente en volquetas, y la iban y la botaban por allá a un, a un, si los que [**taban] muertos, y eso al que iba saliendo lo iban matando".

- G3I1H09C: "y después de esa fecha en adelante, se empezó que a hacer comisiones en las veredas para cuidar las veredas y el pueblo, y la señal era que cuando veían una persona extraña, tocaban cacho o echaban un cohete de pólvora, y eso era una alarma, pero < tremenda > que se formó en esos tiempos".

- G3I1H12L-C: "el que medio arregló eso fue Rojas Pinilla, ese fue el que medio arregló y que hubo el pacto nacional, pero cuando fue eso, yo me acuerdo, yo [**taba] chinche, uno por lo menos a [Suatá] podía llegar, [pa**] Tipacoque no, porque en Tipacoque eran liberales y pasaban de [Suatá] [pa**llá] / matarsen/ eran y pasaban de allá [pa'cá] también, ahí se quedaban (risas), sí, eso era una porquería, eso".

\section{Análisis del discurso del testimonio}

El índice de coocurrencias de categorías que se presenta a continuación, es resultado del análisis realizado en el software Atlas.Ti. La Figura 1 refleja las relaciones entre categorías y subcategorías. Los colores definen la densidad y fundamentación de cada código; por tanto, el más oscuro es el más denso.

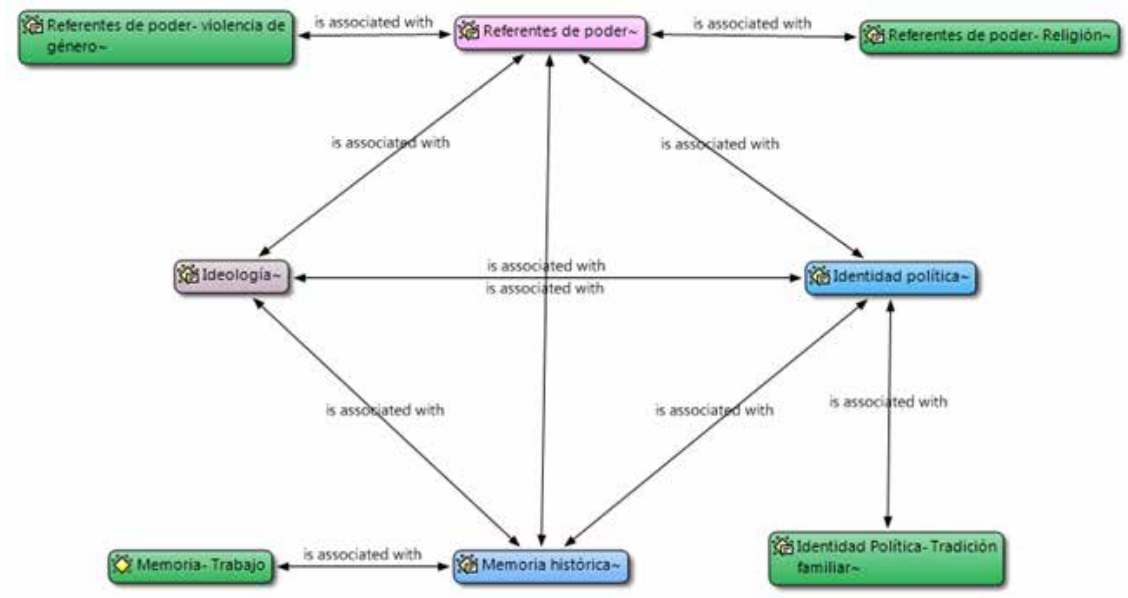

Figura 1. Redes semánticas entre categorías y subcategorías.

Fuente: Atlas.Ti 
La red condensa el índice de coocurrencias entre categorías o códigos (Atlas. Ti). En esta se encuentra una relación subyacente entre los vínculos que establecen la cercanía semántica de las diferentes unidades léxicas. Por otro lado, las coocurrencias establecen las cadenas semánticas, las cuales se entretejen a lo largo del relato. Estas cadenas se relacionan con los recursos que indican significados específicos en el texto, denominados marcas referenciales; ejemplo de ello son los pronombres personales, uno de los elementos lingüísticos establecidos en relaciones a través de mecanismos discursivos, tales como la reiteración, la repetición, la sinonimia, la elipsis y la sustitución.

Es de resaltar que los relatos se encuentran organizados en su superestructura y macroestructura de manera similar; es decir, con una temática de origen político y una secuencia narrativa, en la que el inicio se contextualiza en la época y en el lugar desde donde se narra; el desarrollo enmarca la situación generada a causa del 9 de abril; y el final coincide con el golpe de Estado de Gustavo Rojas Pinilla, quien es representado como pacificador. Además, se describe un conflicto armado entre dos bandos que luchan por poder.

El vínculo entre categorías permite visualizar la manera en que los hablantes por medio del lenguaje focalizan un partido político y lo asumen como suyo, convirtiéndolo no solo en factor de poder, sino en la expresión ideológica de una colectividad específica en que prevalecen unos intereses encargados de favorecer y monopolizar a unos sobre otros, reavivando discrepancias que se conservan y se manifiestan en la actualidad. Entonces, por medio del lenguaje se evidencian las relaciones de poder que varían de acuerdo con la resistencia de los grupos sociales, determinados por la posición identitaria desde donde narra el hablante.

Dicho lo anterior, el componente lingüístico, inherente a las relaciones de poder, refleja el uso del lenguaje como práctica social que posibilita el conocimiento de la experiencia y vivencia de un testigo. De igual modo, los mecanismos discursivos permiten el análisis de los elementos explícitos e implícitos, a través de los cuales se transmiten las impresiones subjetivas o sociales de los boyacenses en 1948.

\section{Conclusiones}

A continuación, se presentan algunas de las conclusiones de esta investigación, que giran en torno a los presupuestos planteados a partir de la influencia de la identidad política en los relatos del 9 de abril.

Así, pues, la identidad política se describe desde la identificación del individuo a una adscripción política, en la cual subyacen formas específicas de hilar una interpretación del pasado, evidentes en los mecanismos discursivos, que explicitan la forma en que los 
referentes de poder constituyen los factores identitarios y de incidencia de los cuales se apropia el hablante, y permiten que su relato sea único y aporte a la memoria histórica del departamento.

En este punto es necesario indicar que la identidad política se hace explícita a través del discurso de quien relata su vida y las acciones llevadas a cabo por parte de las organizaciones en cada comunidad objeto de estudio. Las dos, palabra y acción, se encuentran en correspondencia; en otras palabras, lo que se dice se debe cumplir como fundamento moral, y lo que se hace se convierte en un discurso que tiene como consecuencia la adhesión o el repudio al grupo social.

De acuerdo con Ricoeur (1995), "el relato construye el carácter duradero de un personaje que podemos llamar identidad, al construir la identidad dinámica propia de la historia contada" (p. 344). Es por ello que la identidad de una persona o una comunidad es la historia que se cuenta en sí misma o que otros cuentan sobre ella. La identidad política del narrador se hace evidente a medida que va contando su propia historia, en la que enmarca unas formas específicas de construirla, alterando incluso la secuencia de los sucesos que narra.

Por tanto, en cada uno de los relatos se comprende la integración de la identidad política, como elemento fundamental en la enunciación del contexto, las relaciones de poder, las acciones que ejercen dicho poder y el orden en que se perciben los acontecimientos. Dichos factores identitarios sesgan la representación de las dinámicas sociales de la época, que se expresan por medio del testimonio y dan un sentido específico al relato que demuestra la intención del hablante orientado por los principios del liberalismo y el conservatismo.

En cuanto a las ideologías, como lo afirma Van Dijk (2005), estas controlan y organizan otros tipos de creencias; lo que en los relatos se muestra como el dominio de los pensamientos, actitudes y acciones de los integrantes del grupo social, por medio de la religión, de los presupuestos familiares y de género que imperan en el mismo relato. Se rigen por unos principios que permiten establecer o legitimar formas jerárquicas de autoridad mediadas por el poder y que se hacen evidentes a partir de los mecanismos discursivos usados por el hablante y ratificados a lo largo del tiempo, para construir un discurso que representa la interpretación de la realidad de un pasado del cual fue testigo.

Es así como las disputas bipartidistas, organizadas como medio del control dominante en la sociedad boyacense, demuestran las conceptualizaciones teóricas aportadas por Van Dijk (1994), Castells (2009), Foucault (2010) y Bourdieu (2008), donde se coincide y pondera al lenguaje como componente fundamental de las relaciones 
de poder que estriban en la postura ideológica (liberal o conservadora) desde donde se narra.

Dicha postura se demuestra en los factores lingüísticos que predominan a través de las pronominalizaciones en tercera persona y las elisiones de las colectividades que ejercen una acción presenciada en los verbos, los cuales permiten describir los referentes de poder, como aquellos que, a partir del lenguaje, dan a conocer entidades y personajes que ejercen una forma de dominación valiéndose de cargos representativos dentro de un sistema de gobierno y de líderes ilegitimados, y muestran cómo las ideologías manifestadas en el año 1948 se convierten en fundantes de un control social generador de una guerra bipartidista.

Aunado a lo anterior, los recursos discursivos que se identifican cuando se usa el pronombre se y con mayor reiteración en los relatos es la metáfora, debido a que enmascara la responsabilidad de los acontecimientos ocurridos, como es el caso de la guerra y los agentes encargados de formarla; el pronombre y la metáfora representan la estrategia de elisión de los actores sociales que toman parte en la situación que se creó de 1948 a 1953, aproximadamente, en Colombia. Estas referencias elípticas coinciden con la categoría referentes de poder a la que pertenecen los agentes que luchan por alguna forma de dominación social.

En cuanto a la lexicalización en el habla campesina, esta se representa en el uso de unidades léxicas con un cambio semántico de acuerdo con el contexto, casi siempre metafórico. En este, la forma original del enunciado se convierte en una unidad polisémica, que adquiere en el proceso un significado nuevo evidente en la interpretación de los relatos. Las lexicalizaciones hacen parte de la esencia de la cultura y se hacen explícitas a través de la experiencia vivida durante la época en el departamento.

Por otro lado, el significado local que se visualiza en los enunciados tiene coocurrencia con la categoría de memoria histórica, debido al sentido otorgado al conjunto de sucesos que conforman la representación del 9 de abril de 1948, y se describe en la selección de términos que muestran un problema mediante el uso de adjetivos, deícticos sociales e interjecciones; los cuales, además, se unen tanto para eludir información, como para explicar acciones específicas que sucedieron en el departamento de Boyacá. Estos se presentan como la justificación de los hablantes para no continuar con el tema, llevan al uso frecuente de argumentos estereotipados que ocultan la experiencia individual de quien se presenta como testigo, pero manifiestan la aparición de minorías opositoras a quienes mantienen el poder y representan las disputas de amigo contra enemigo. 
De acuerdo con los resultados y la discusión que giró en torno de estos, los hallazgos y aportes obtenidos en esta investigación permiten comprender cómo una identidad política incide en la construcción de un suceso que pertenece a la interpretación de la realidad de un testigo, con base en mecanismos discursivos como aporte que permite integrar la lingüística en la reinterpretación de un suceso histórico, rescata consigo la tradición oral boyacense y resalta la ruta metodológica como una contribución a investigaciones que deseen articular desde el análisis del discurso, la oralidad, las estructuras y mecanismos discursivos a la producción de sentido y memoria histórica.

\section{Referencias}

Arendt, H. (2009). La condición humana (1.a ed.- 5.a reimp). Barcelona: Paidós.

Bal, M. (1990). Teoría de la narrativa. Una introducción a la narratología. Madrid: Cátedra.

Bohórquez-Aunta, C. \& González-González, E. (2018). Identidad política en los relatos del 9 de abril en Boyacá. (Tesis de la Maestría en Lingüística). Universidad Pedagógica y Tecnológica de Colombia, Tunja, Colombia.

Bourdieu, P. (2008). ¿Qué significa hablar? Madrid: Akal.

Castells, M. (2009). Comunicación y poder. Barcelona: Alianza.

Centro Nacional de Memoria Histórica -CNMH-. (2013). Recordar y narrar el conflicto. Herramientas para reconstruir memoria bistórica. Bogotá: Imprenta Nacional de Colombia.

Corbetta, P. (2003). Metodología y técnicas de investigación social. Madrid: McGraw-Hill.

Duranti, A. (2000). Antropología lingüística. Madrid: Cambridge University.

Fillmore, L. (1979). Individual Differences in Second Language Acquisition. In Individual Differences in Language Ability and Language Behavior (pp. 203-228). New York: Academic Press.

Foucault., M. (2010). Vigilar y castigar: nacimiento de la prisión. (1.a reimp.). Buenos Aires: Siglo XXI.

Fressoli, G. (2010). Memoria y recuerdo en la obra de Walter Benjamin. Revista Afuera, 5(9). Recuperado de http://www.revistaafuera.com/articulo.php?id $=51 \&$ nro $=9$

Greene, S. (2004). Social Identity Theory and Party Identification. Social Science Quarterly, 85(1), 136-153. doi:10.1111/j.0038-4941.2004.08501010.x. 
Llisterri, J. (1999). Etiquetado, transcripción y codificación de corpus orales. Seminario de Industrias de la Lengua.

Meza, S. (2007). El discurso testimonial: subalternidad, representación y enunciación bivocal en Sueño con menguante. Biografía de una machi y Hasta no verte Jesús mío (Doctoral dissertation). Universidad de Chile, Santiago de Chile.

Nora, P. (1993). Les lieux de mémoire (Los lugares de la memoria). París: Gallimard.

Nora, P. (2008). Pierre Nora en Les lieux de mémoire. Montevideo: Trilce.

Portelli, A. (1991). The Death of Luigi Trastulli and other Stories. New York: State University of New York Press.

Ricoeur, P. (1995). Tiempo y narración. Relato bistórico. Vol. I. México: Siglo XXI.

Ricoeur, P. (2004). La memoria, la historia, el olvido. Buenos Aires: Fondo de Cultura Económica.

Sampieri, R. H. (1998). Metodología de la investigación. Vol. 6. México: McGraw-Hill.

Van Dijk, T. (1994). Discurso, poder y cognición social. Cuadernos de la Maestría en Lingüística, 2, 1-92.

Van Dijk, T. (2002, jun.). El análisis crítico del discurso y el pensamiento social. Athenea Digital. Revista de Pensamiento e Investigación Social, (1). Recuperado de https:// atheneadigital.net/article/view/n1-van

Van Dijk, T. (2005). Ideología y análisis del discurso. Utopía y Praxis Latinoamericana, 10(29).

Wodak, R. (2003). El enfoque histórico del discurso. En R. Wodak \& M. Meyer (eds.), Métodos de análisis críticos del discurso (pp. 101-141). Barcelona: Gedisa. 